\title{
INTO THE VALLEY OF ETHICS: PROFESSIONAL RESPONSIBILITY AND EDUCATIONAL REFORM
}

\author{
DEBORAH L. RHODE
}

\section{INTRODUCTION}

In a recent keynote address on professional responsibility, Supreme Court Justice Ruth Bader Ginsburg recounted a well-loved story about a student's first encounter with legal ethics. The professor in one of the core first-year courses was describing a lawyer's tactic that left the student "bothered and bewildered." "But what about ethics?," the student asked. "Ethics," the professor frostily informed him, "is taught in the second year."

For most of its history, however, American legal education has aspired to teach professional responsibility by a more pervasive method. ${ }^{2}$ This essay charts efforts to realize that aspiration, not just in theory but in practice.

Since the mid-1970s, the American Bar Association has required accredited law schools to provide instruction in professional responsibility. ${ }^{3}$ Although the vast majority have met that requirement through a mandatory ethics course, some schools, including my home institution, Stanford University Law School, have chosen instead to integrate ethical issues into the core curriculum. A still smaller number of schools has combined these approaches. This essay reviews the rewards and the challenges of pervasive ethics initiatives.

Copyright $(1) 1996$ by Law and Contemporary Problems
* Professor of Law and Director, Keck Center on Legal Ethics and the Legal Profession, Stanford University.

The research support from the W.M. Keck Foundation, the research assistance of Jon Blazer, Edward Frueh, and Linda Holmes, and the comments of Paul Brest, David Luban, Thomas Metzloff, and William Simon are greatly appreciated.

1. Justice Ruth Bader Ginsburg, Supreme Court Pronouncements on the Conduct of Lawyers, Keynote Address at the Hofstra University Law School Conference on Legal Ethics: The Core Issues (Mar. 10, 1996).

2. The pervasive method of legal ethics education refers to the process of incorporating ethics instruction into all aspects of the legal curriculum. Under this approach, many substantive courses would devote a portion of class time to studying questions of professional responsibility.

3. AMERICAN BAR ASSOCIATION, STANDARDS FOR THE APPROVAL OF LAW SCHOOLS std. 302(a)(iv) (1993) [hereinafter ABA STANDARDS]. The Standards mandate that accredited law schools "require of all candidates ... instruction in the duties and responsibilities of the legal profession. Such required instruction need not be limited to any pedagogical method as long as the history, goals, structure, and responsibilities of the legal profession and its members, including the ABA Model Rules of Professional Conduct, are all covered." Id. 
I have argued at length elsewhere that law schools should address issues of professional responsibility throughout the curriculum as well as in specialized courses. ${ }^{4}$ I will not restate that argument here except to note its central premise: Legal ethics deserves discussion in all substantive areas because it arises in all substantive areas. Faculty who decline, explicitly or implicitly, to address ethical issues encourage future practitioners to do the same. To confine professional responsibility discussions to a single required course marginalizes their importance and undermines their most important message: that moral responsibility is a crucial constituent of all legal practice. This essay is directed to audiences who share that view or who are at least interested in its curricular implications.

The rewards of a pervasive approach to professional responsibility instruction are substantial, but so are the barriers to realizing them. Stanford's experience is illuminating on both counts. Its initiatives, together with similar efforts at other institutions, suggest some general insights about the value of curricular integration.

This essay begins in Part II by examining the central features of effective professional responsibility instruction. Part III then addresses the most common criticisms of legal ethics curricula. Part IV concludes by suggesting that the most successful approach is likely to combine pervasive instruction and some required courses.

\section{II}

\section{EFFECTIVE ETHICS INSTRUCTION}

David Luban, my coauthor on a legal ethics casebook, once opened a workshop on teaching legal ethics with Tolstoy's observation that every unhappy family is unhappy in its own way. ${ }^{5}$ Luban went on to suggest that the same is true of every professional responsibility course. There are inherent problems and infinite ways to fail in teaching this subject, particularly to captive graduatelevel audiences. I personally have experimented with most forms of failure, and the following discussion builds on the experiences that I have not yet managed to repress.

Over the last sixteen years, I have taught professional responsibility at various law schools and in various incarnations. My experiences have included mandatory upperlevel courses ranging from fifty to 150 students, small seminars of under ten students, and almost everything in between. Some of these courses have provided a brief overview for first-year students or an advanced, intensive program for third-year students. I have relied on lectures, role-plays, case histories, hypothetical problems, videos, and guests from practice and related academic disciplines.

4. Deborah L. RHOde, PRofessional Responsibiltry: ETHICS BY THE PERVASIVE METHOD 3-8 (1994); Deborah L. Rhode, Ethics by the Pervasive Method, 42 J. LEGAL EDUC. 31 (1992).

5. David Luban, Epistemology and Moral Education, 33 J. LEGAL Educ. 636 (1983). 
The one context in which $I$ have not taught professional responsibility is clinics, and, partly for that reason, I am convinced that they may be the best settings for such instruction. ${ }^{6}$ However, they are also one of the most expensive ways of teaching legal ethics and should not be a substitute either for the pervasive approach or for classes focusing on specialized issues such as bar regulatory structures. Indeed, to give clinics a monopoly on professional responsibility instruction would further marginalize its significance in the eyes of many faculty and students.

My experience with various teaching formats, together with secondary literature, student and faculty survey responses, and war stories from other colleagues, leads me to several general conclusions and one overarching disclaimer. ${ }^{7}$ The disclaimer falls along the lines of the social science cliche that no generalization is worth anything, including this one. For every tendency that I am about to describe, there are multiple exceptions. Any strategy has tradeoffs. Gifted teachers can succeed with almost any professional responsibility approach; unmotivated or uninformed teachers can mess up the most engaging material. But accumulated wisdom on ethics instruction suggests that some approaches are more likely to work than others. Effective programs generally require a strong institutional commitment to the subject, together with well-structured course materials and methods for evaluating student performance. Other important features include interactive teaching formats, opportunities for faculty and student choice, and tolerant classroom approaches that are neither value-neutral nor overly rule-bound.

\section{A. Institutional Commitment}

The most important characteristic of effective professional responsibility programs is the message that the subject is itself important. Although few faculty would disagree in principle, they can inadvertently sabotage that signal in practice. Failure to include significant ethics material in course assignments,

6. For an argument about the comparative virtues of clinical approaches, see David Luban \& Michael Millemann, Good Judgement: Ethics Teaching in Dark Times, 9 GEO. J. LEGAL ETHICS 31 (1995). For general discussion of the value of such approaches, see Mary C. Daly et al., Contextualizing Professional Responsibility: A New Curriculum for a New Century, 58 LAW \& CONTEMP. PROBS. 193 (Summer/Autumn 1995); Christine Mary Venter, Encouraging Personal Responsibility-An Alternative Approach to Teaching Legal Ethics, 58 LAW \& CONTEMP. PROBS. 287 (Summer/Autumn 1995). Some of the same advantages can be achieved through simulation. See Robert P. Burns, Teaching the Basic Ethics Class through Simulation: The Northwestern Program in Advocacy and Professionalism, 58 LAW \& ConTemp. Probs. 37 (Summer/Autumn 1995).

7. My data include a survey of the entire Stanford student body in 1991 (response rate $40 \%$ ), a survey of the first year Stanford class in 1994 (response rate $74 \%$ ), and a survey of 155 second- and third-year students enrolled in my 1995 New York University professional responsibility class (response rate $33 \%$ ). About two-thirds of the entire Stanford faculty completed questionnaires in 1991, and about one-third of participating faculty completed questionnaires in 1995. Both student and faculty questionnaires focused on the desirability and adequacy of instruction through the pervasive method and through a required ethics course. Copies of all surveys and questionnaires are on file with the author. 
in classroom discussions, and in exams or written assignments will undercut the basic purpose of required coverage.

The most common problem is reliance on a pervasive approach that is not, in fact, pervasive. Although Stanford has long struggled with that problem, it has also made striking progress. After years of gentle administrative prodding by Dean Paul Brest, the school recently made a major effort to strengthen faculty support. With substantial assistance from the W.M. Keck Foundation, that effort has now produced an impressive institutional commitment. In the fall of 1994 and 1995, all Stanford faculty members teaching mandatory firstyear courses agreed to set aside at least two full class hours for ethical discussion, accompanied by significant written materials. ${ }^{8}$ In addition, first-year students have been required to attend a number of special professional responsibility programs and to complete an exercise or written assignment. The programs have been subject to ongoing evaluation and revision. In the spring of 1996, the faculty decided to encourage but not require first-year instructors to continue covering professional responsibility issues. The faculty also added a requirement that students complete at least one unit of upperlevel instruction in ethics, either through a basic professional responsibility course or through other substantive courses that include significant ethics material.

These curricular initiatives reflect a significant advance over preceding years. First-year courses now consistently cover substantial legal ethics material, much of it published in Professional Responsibility: Ethics by the Pervasive Method. ${ }^{9}$ The book includes nine chapters that survey core concepts in professional responsibility and ten chapters that integrate ethical issues into basic first-year and upperlevel courses. ${ }^{10}$ At Stanford, the core-concept chapters form the basis of the introductory professional responsibility sessions for first-year students and the foundation for an upperlevel elective professional responsibility course. The substantive chapters provide material that professors may adapt for their individual classes.

This material raises a broad range of issues that corresponds to the substantive framework of leading casebooks. Coverage includes relevant provisions of the Model Rules of Professional Conduct and the Model Code of Professional Responsibility, as well as leading cases, scholarly and journalistic commentary, bar ethics rulings, and related interdisciplinary material. These selections are structured around hypothetical problems that are not entirely hypothetical. Almost all of them draw on actual situations involving real lives

8. Through support from the W.M. Keck Foundation, faculty were eligible for summer stipends to add materials for first-year courses. Some professors also received more substantial stipends to develop upperlevel courses that devoted substantial attention to ethics issues.

9. RHODE, PROFESSIONAL RESPONSIBILITY, supra note 4.

10. The overview chapters address the following: traditions of moral reasoning; regulation of the profession; the advocate's role; the adversary system; confidentiality; conflicts of interest; negotiation and mediation; and the lawyer-client relationship. The substantive chapters involve civil procedure, constitutional law, contracts, corporate law, criminal law and procedure, evidence and trial advocacy, family law, property, tax, and torts. 
and real consequences. Many professors add or substitute other texts, legal cases, videotapes, and presentations by practitioners.

To assist faculty in course preparation, Stanford's Keck Center now distributes an annotated bibliography of innovative teaching materials on legal ethics and the legal profession. ${ }^{11}$ This bibliography includes both published and unpublished texts and videos, indexed by author and subject matter. The point of this bibliography, as well as my own text on the pervasive method, is to accommodate a wide variety of teaching preferences and priorities. ${ }^{12}$

Although substantial room for progress remains, the availability of such materials, together with an increased institutional commitment, has greatly improved Stanford's ethics program. In recent surveys, most students indicated that professional responsibility is an important and interesting topic, and that professors who are committed to the subject provide effective instruction. However, questionnaire responses also revealed that ethics discussions are still not sufficiently frequent nor well integrated into first-year courses. As one student noted, professional responsibility coverage too often seems "somewhat of an add on .... . It feels like we are [only] doing an obligatory ethics problem here and there" rather than engaging in sustained analysis.

Students also commented on a related problem: Professors who subtly or not so subtly conveyed a sense that ethics is unimportant. A few faculty members saved professional responsibility issues for "the last five minutes of class," made clear that such issues would not be on the exam, or appeared apologetic about having to take "time away from the 'substance' of the course." Picking up on these cues, some students did not treat ethics issues seriously; they neither did the reading nor took notes on class discussions. This, in turn, reinforced certain faculty members' reluctance to devote substantial time to professional responsibility concerns. The result was a self-perpetuating cycle. As one professor concluded, "Unless I test on it (which would alter my course substantially), the students treat [ethics material] as a lark."

The solution follows obviously from the diagnosis. Pervasive ethics will work only if professors are in fact willing to alter their courses and to include ethics issues on exams. Summarizing a common view, one student concluded that "ethics should definitely be incorporated into all of the courses. . . But there needs to be more of [a] real commitment to do that."

A related problem involves over-reliance on supplemental ungraded ethics programs. Scheduling these events when students have strong competing concerns can exacerbate the problem. Like other law schools, Stanford has had mixed experience with including special ethics programs during orientation week. Attempting to convey crucial substantive material in these sessions is usually a mistake; first-year students are more likely to worry about whether

11. The bibliography is reprinted in this issue of Law and Contemporary Problems. Deborah L. Rhode, Annotated Bibliography of Materials on Teaching Legal Ethics, 58 LAW \& CONTEMP. PROBS. 363 (Summer/Autumn 1995).

12. RHODE, PROFESSIONAL RESPONSIBILITY, supra note 4. 
they can get their phones connected than whether they understand the difference between the Model Code and the Model Rules. However, raising ethical issues at the outset of law school can also have significant symbolic value. The challenge is to find compelling material, such as film, case history, or a panel on a controversial topic that engages without overwhelming students.

Another common problem is scheduling intensive ungraded programs without giving students enough release time from other course work. Stanford once made this mistake by requiring participation in a negotiation exercise as a supplement to regular courseloads. Student questionnaire responses revealed significant resentment. Comments also centered on the "tacit statement" of priorities that an ungraded exercise conveyed. As one student concluded, "people will get into [ethics coursework]," but only if "it's graded and taught with enthusiasm."

\section{B. Interactive Formats}

When it comes to class size, smaller is better in most law school contexts, but even more so in professional responsibility courses. Legal ethics instruction needs settings that encourage broad-based participation, candid interchanges, and direct personal engagement. This is the consensus of most experts, including those who study moral education. Recent studies find that interactive learning, such as problem solving and role playing, is the best way of enhancing skills in moral analysis. ${ }^{13}$

Stanford's experience bears this out. The pervasive ethics initiative that students rated highest in 1994 was a negotiation exercise. Developed under a Keck Foundation grant at Columbia Law School, the exercise involved twoperson teams that represented either the husband or wife in a divorce case. Students had to grapple with a broad range of issues including client fraud, coercive tactics, lawyer-client conflicts of interest, and concerns of an unrepresented child. Many participants liked this opportunity to address concrete problems and to see how they and their classmates would react "when put in a real life situation." For some students, the exercise was a sobering reminder that "ethics is easier said than done" and an example of "how ethical resolve can be shaken in practice." For other individuals, role playing offered a welcome "break from the monotony" of large lectures and abstract discussions. Students at other law schools make similar points. It is, as one individual noted,

13. James Rest \& Stephen J. Thoma, Educational Programs and Interventions, in MoRAL DEVELOPMENT: ADVANCES IN RESEARCH AND THEORY 59-78 (James Rest et al. eds., 1986); Joseph Volker, Life Experiences and Developmental Pathways, in MORAL DEVELOPMENT, supra, at 3, 14, 31-42; James E. Moliterno, An Analysis of Ethics Teaching in Law Schools: Replacing Lost Benefits of the Apprentice System in the Academic Atmosphere, 60 U. CIN. L. REV. 83 (1991); James E. Moliterno, Teaching Legal Ethics in a Program of Comprehensive Skills Development, 15 J. LEGAL PROF. 145 (1990); Donnie J. Self et al., The Effect of Teaching Medical Ethics on Medical Students' Moral Reasoning, 64 ACAD. MED. $755-59$ (1989). 
"not easy to discuss Durkheim with a hundred of your closest friends." 14 Nor are such discussions likely to be as valuable for most individuals as are more practice-oriented interchanges in smaller classroom settings.

\section{Faculty and Student Choice}

Nothing poisons the classroom atmosphere more than individuals who do not want to be there. As subsequent discussion indicates, a substantial number of faculty and students feel that way about legal ethics discussions. The problem is not wholly avoidable as long as accreditation standards require law schools to provide professional responsibility instruction. If a school decides (appropriately in my view) that such instruction will be effective only if integrated throughout the curriculum, then some professors probably will be unwilling participants in the enterprise.

It is possible, however, to reduce resistance by giving students and faculty a measure of choice about their involvement. At Stanford, for example, firstyear teachers who do not wish to provide professional responsibility instruction have had the option of giving up class hours for programs taught by colleagues and visiting practitioners. Upperlevel students will now have the oppotunity to satisfy their ethics requirement by completing either the basic professional responsibility class, or some other elective that presents significant ethics material, such as Negotiation, Trial Advocacy, Tax, Family Law, Criminal Defense, or Prosecution.

Any method of handling professional responsibility requirements presents tradeoffs. Allowing first-year professors to opt out or to cede their ethics time to special programs is hardly an ideal solution; that strategy discourages students from raising ethics questions at other points during the semester and makes it difficult to include such material on the final exam. Law schools teach in subtexts as well as texts, and a faculty member's pervasive silence about professional responsibility sends a clear and counterproductive message. Yet as student evaluations also make clear, reluctant coverage sends the same signal and occupies time that could more profitably be spent by colleagues committed to the enterprise. On balance, an opt-out provision for faculty makes sense. It is encouraging that, in the last two years at Stanford, faculty have rarely chosen that option.

Students, however, should not receive the same prerogative, since those who are likely to exercise it may be the ones who most need exposure to ethics issues. But maximizing choice for students is more likely to promote engaged discussion than requiring everyone to take a standardized professional responsibility class. That is particularly true if the requirement involves an upperlevel course. As Stephen Bundy notes, "the requirement chafe[s] more

14. Stephen McG. Bundy, Ethics Education in the First Year: An Experiment, 58 LAW \& CONTEMP. PROBS. 19 (Summer/Autumn 1995). 
severely once students [have] had a taste of freedom in course selection."15 Yet there are also advantages in putting mandatory coverage in the second or third year; students have a better understanding of professional responsibility issues after they have had broader exposure to legal rules and practice norms.

It also helps if individuals are able to ground their ethics discussions in the substantive areas that hold greatest interest to them personally. One of Stanford students' principal criticisms of the first-year program was that some of the sessions, particularly the materials on criminal practice and family law, did not seem relevant to their own career plans. While that difficulty cannot be escaped entirely, it can be mitigated by focusing on diverse practice areas in the first year and by offering a variety of ethics-related electives in the second and third years.

Choice is equally critical in the course material available for curricular integration. As noted earlier, my text on teaching ethics pervasively attempts to accommodate different teaching approaches by including a broad array of issues and an equally wide range of doctrinal and interdisciplinary material. The text also offers opportunities to address questions involving race, class, and gender, which are not always well represented in casebooks. For example, my chapter on constitutional law includes ethical problems concerning government lawyers' responsibilities in the World War II Japanese internment cases, class action counsels' obligations in school desegregation cases, and feminist advocates' difficulties in identifying "women's interests" on issues like pornography regulation. ${ }^{16}$ How best to address such concerns will, of course, vary considerably among law school classes. To structure effective presentations, faculty need a broad menu of materials from which to choose.

\section{Classroom Tolerance and Codified Standards}

Professional responsibility inevitably involves issues of personal responsibility on which students have strong views. The challenge for legal education is to create classroom atmospheres that encourage candid and self-critical exploration of competing values. Problems run in two quite different directions. One risk is that professors will allow their own perspectives to dominate discussion and stifle opposing views. Alternatively, if faculty studiously avoid taking a position, the course can end up undermining moral judgment. By offering students a steady diet of seemingly insoluble dilemmas, professional responsibility classes can inadvertently foster skepticism, relativism, and cynicism. Moreover, since total objectivity is never possible, faculty who attempt such a stance often are masking values that should be open for challenge.

The preferable alternative is a classroom climate that encourages toleration without eroding commitment. While on many issues there are no objectively valid answers, not all answers are equally valid. Some are more consistent,

15. Id. at 22 .

16. RHODE, PROFESSIONAL RESPONSIBILITY, supra note 4, at 506-25. 
coherent, and respectful of evidence. Nor do all issues of professional ethics present intractable personal dilemmas. Many regulatory issues call for the same skills of legal interpretation and policy analysis that are standard fare in other law school classes. We do not expect faculty or students to suspend judgment in those contexts; we should view professional responsibility courses no differently.

A related set of risks involves the role of bar ethical codes in shaping ethics curricula. Here again, the difficulties run in opposite directions. As William Simon has noted, rule-bound courses that focus on preparing students for the bar can readily turn into legal ethics without the ethics. ${ }^{17}$ In contexts where codified standards are ambiguous, silent, self-serving, or undemanding, students need exposure to competing perspectives. Yet professors who try to teach a course in moral philosophy will end up alienating or speaking past a substantial part of their audience. In one telling case, a student (not at Stanford) advised a classmate to avoid taking a particular professional responsibility course because the professor "asks a lot of uncomfortable questions about what you think is right and never spends any time teaching the rules ...."18

The difficulty in striking the right balance between codes and more valueladen materials is compounded by students' inconsistent preferences. Some responses to the Stanford survey favored greater attention to the rules, a focus that appeared preferable to "meandering dorm-like discussions" of moral issues. By contrast, other students found the rules "useless-they tell you how to get around being ethical not how to be ethical."

These challenges in structuring an effective professional responsibility class are not unique to this subject. Any course can present similar Goldilocks dilemmas: Teachers can always provide too much or not enough of their own views or of codified rules. Moreover, faculty who are truly committed to the subject can often succeed with approaches that fall on either side of the continuum.

Interestingly enough, the two Stanford professors who received the most positive ethics evaluations for first-year courses employed quite different approaches. ${ }^{19}$ One was contracts professor who set aside two full class sessions for professional responsibility discussions. She assigned material from my text concerning issues of duress, undue influence, unconscionability, and unilateral mistakes. Included in this material was a representative range of questions involving professional responsibility. For example, what are lawyers' obligations of candor, confidentiality, and client loyalty when they know that an opposing party is ignorant of a material fact or is about to sign a contract with an

17. William H. Simon, The Trouble With Legal Ethics, 41 J. LEGAL EDUC. 65, 66 (1991).

18. Daniel S. Kleinberger, Ethos and Conscience-A Rejoinder, 21 CONN. L. REV. 397, 401 n.23 (1989).

19. These approaches are analyzed in depth in Jon Blazer, Student Responses to Stanford Law School's Efforts at Pervasive Ethics Instruction (1995) (unpublished student paper, on file with the author). 
unenforceable clause? What kinds of contractual conditions can law firms impose on departing partners? Should attorney whistleblowers have rights to sue for wrongful discharge? Under what, if any circumstances should lawyers police the fairness of a bargain? Such questions provide opportunities to focus both on Model Rule provisions and on broader issues of professional conduct. Students generally liked the mix, and several noted with approval that this professor was not "afraid to say some behavior is flat out unethical."

By contrast, another faculty member was equally successful with a less structured and less rule-oriented approach. Her course on civil procedure integrated ethics issues into multiple class sessions, relied more heavily on spontaneous discussions, and focused students' attention on how they personally would resolve difficult dilemmas. An invited practitioner who discussed professional responsibility issues in sexual harassment cases was also highly effective. Her presentation underscored the relevance of ethical questions in daily practice.

Such examples reinforce the point noted earlier; commitment to the subject is more crucial than choice of technique. But it is also true that efforts to build such commitment bump up against some long-standing obstacles. Reservations about the value of professional responsibility instruction remain common among both faculty and students. As the following discussion suggests, efforts to address such skepticism should be a central part of any curricular integration program.

\section{III}

\section{The Rationale for Pervasive Ethics}

Although an extended defense of professional responsibility instruction is beyond the scope of this article, the two most common objections deserve at least brief review. One criticism involves the ineffectiveness of moral education in general; the other concerns problems with curricular integration in particular.

\section{A. Legal Education, Ethical Values, and Ethical Conduct}

The first objection is that postgraduate education in moral responsibility offers too little too late. As one Stanford student put it, "trying to teach ethical standards in the classroom is a total waste of time-mere discussion won't change attitudes that have been shaped by twenty-odd years of experience." Another student added, "[u]nless there is something that we need to know that we didn't learn in kindergarten, it's not worth the time or money. Not only are there many important and opaque legal issues we learn in [our] first year, but we're paying $\$ 20,000$ to spend our time on them." A related claim is that even if law school education has some marginal effect on student attitudes, it will have little impact on their later practice. Moral conduct is highly situational, 
and critics argue that contextual pressures are likely to dwarf any lingering effects of classroom moralizing. ${ }^{20}$

There is something to these claims, but not nearly as much as some faculty and students imagine. First, ethical values are by no means as fixed as critics contend. Recent psychological research indicates that significant changes occur during early adulthood in peoples' basic strategies for dealing with moral issues. $^{21}$ Through interactive education, individuals can enhance skills in ethical analysis and increase their awareness of the situational factors that skew judgment. Over 100 studies evaluating ethics courses find that well designed curricula can significantly improve capacities for moral reasoning. ${ }^{22}$

Moreover, not all professional responsibility issues involve matters of deep moral significance. Some concern bar regulatory standards and legal decisions that students will not have encountered before law school and that are not qualitatively different from the material in other courses. Even on more valueladen issues, professional standards sometimes depart from what personal moral intuitions might dictate. Future practitioners need to know where the bar draws the lines before they are in a position to cross one.

Despite the importance of situational pressures, psychological research also generally finds some modest relationship between moral judgment and moral behavior. ${ }^{23}$ How individuals evaluate the consequences of their actions can be critical in shaping conduct, and education can affect those evaluative processes. It can also make individuals aware of ways that economic incentives, peer pressures, structures of authority, and diffusion of responsibility affect decisionmaking. ${ }^{24}$ Most lawyers who have taken legal ethics courses give them some credit for helping to resolve ethical issues in practice. ${ }^{25}$ Surveyed lawyers and students also have favored maintaining or expanding ethics coverage in law

20. A vast array of research documents the variability of moral conduct in response to stress, competition, authority, peer influence, financial incentives, and time pressure. See the studies summarized in Rhode, Ethics by the Pervasive Method, supra note 4.

21. James R. Rest, Can Ethics be Taught in Professional Schools? The Psychological Research, in EAsier SAID Than Done 22, 23-24 (1988); James R. Rest et al., An Overview of the Psychology of Morality, in MORAL DEVELOPMENT, supra note 13, at 3, 14.

22. Rest, supra note 21, at 23-24; see also James S. Leming, Curricular Effectiveness in MoralValues Education: A Review of Research, 10 J. MORAL EDUC. 147 (1981).

23. Albert Bandura, Social Cognitive Theory of Moral Thought and Action, in HANDBOOK OF MoRAl Behavior AND DEVElopMENT 45, 53 (William M. Kurtines \& Jacob L. Gerwitz eds., 1991); Walter Mischel \& Harriet N. Mischel, A Cognitive Social-Learning Approach to Morality and SelfRegulation, in MORAL DEVELOPMENT AND BEHAVIOR: THEORY, RESEARCH, AND SOCIAL ISSUES 84, 101-07 (Thomas Likona ed., 1976); Augusto Blasi, Bridging Moral Cognition and Moral Action: $A$ Critical Review of the Literature, 88 PSYCHOL. BULL. 1 (1980)(concluding that most recent studies suggest a correlation between developmental stages in moral reasoning and altruism, honesty, and resistance to peer pressure).

24. For discussion of these general goals of professional responsibility instruction, see David B. Wilkins, Redefining the "Professional" in Professional Ethics: An Interdisciplinary Approach to Teaching Professionalism, 58 LAw \& CONTEMP. PROBS. 241 (Summer/Autumn 1995).

25. Frances K. ZEMANS \& Victor G. Rosenblum, The MaKing of A Public Profession $176-$ 77 (1981). 
schools. ${ }^{26}$ Indeed, four out of five Stanford students want professors to devote more attention to professional responsibility issues. There is, in short, stronger evidence concerning the value of professional responsibility instruction than of most legal education. ${ }^{27}$

\section{B. Curricular Integration}

For some faculty and students, the problem is not legal ethics instruction per se but rather the attempts to integrate it into the core curriculum. Opponents raise two primary concerns, one practical, the other personal. The first concern is that curricular integration risks unsystematic and uninformed coverage. Many issues, such as candor, confidentiality, and conflicts of interest, cut across substantive areas. A pervasive method risks shallow and repetitive treatment, rather than the in-depth coverage available in a single, focused course. Other issues, such as bar regulatory structures, seldom arise naturally outside of professional responsibility classes. As Stephen Bundy notes,

by giving the pieces of legal ethics a home everywhere, [an exclusively pervasive approach] effectively deprives its core concepts of a home anywhere .... [Students] need a place .... [to] confront in any probing or systematic way, the central ethical concepts . . . and regulatory alternatives that underlie all areas of professional ethics and regulation. ${ }^{28}$

The obvious answer to this objection is that pervasive coverage should serve to supplement, not substitute for, separate coursework focused specifically on ethics. Minimal coordination can prevent substantial gaps or overlaps. Stanford has attempted to minimize such problems by surveying first-year faculty about their intended materials and holding one general meeting to discuss these plans.

The second major concern is that most faculty lack expertise in legal ethics issues. This has an equally straightforward solution. It is not difficult to develop familiarity with some basic professional responsibility concerns that fit naturally with substantive coverage. Course materials specifically designed for that purpose are now readily accessible. ${ }^{29}$

Of course, some professors will always feel discomfort wandering into a substantive area outside their expertise. This is especially true of issues like conflicts of interest, which have attracted an increasingly complex body of law. A little knowledge feels like a dangerous thing. But an increasing array of background materials is now available to address those concerns. A major objective of my own pervasive ethics text is to put in broader context professional responsibility topics that arise in core courses. To that end, my book includes extensive cross references; it links problems in substantive law chapters such as contracts and torts to relevant overview chapters on confidenti-

26. Id. at 180

27. Zemans and Rosenblum's study suggests that legal education in general does a poor job in preparing future lawyers for many of the tasks that are most crucial in practice. See generally id.

28. Bundy, supra note 14, at [text with note 28].

29. See RHODE, PROFESSIONAL RESPONSIBILITY, supra note 4. A full bibliography of such materials is available from the Keck Center on Legal Ethics and the Legal Profession at Stanford. 
ality, conflicts of interest, the advocate's role, and so forth. Professors who want to make sure that they fully understand the applicable rules and policy considerations can read this overview material and assign or summarize any part that they find important for their own subject area. An extensive teacher's manual provides further assistance and helps nonexperts anticipate students' questions and concerns.

The real problem is not that most faculty are unable to address professional responsibility issues with reasonable competence in core courses. It is rather that some would prefer not to do so. Individuals who already feel overextended may not want to invest the start-up costs in mastering new materials. Others worry about entrapment in "touchy feely" or platitudinous discussions. ${ }^{30}$

Conversations involving personal moral commitments often appear particularly difficult to structure. Many students are especially invested in ethical questions. They can also be intolerant and insufficiently self-critical in their views, and readily frustrated by constraints on participation in large classes. The simplest way for faculty to avoid these difficulties is to avoid any topic that produces them. As one Stanford professor candidly put it, "[p]ersonally, I would prefer to teach torts. Can't the experts do this [ethics material]?" Well, of course we can, and at most schools, we do. But as earlier discussion suggested, this delegation also carries a cost. Treating professional responsibility as someone else's responsibility encourages future lawyers to do the same.

\section{IV}

\section{CONCLUSION}

While integrating ethical issues poses some special challenges, it also offers some special rewards. For many students, these discussions are among their most memorable classroom experiences. At issue is how individuals want to live their professional lives, and students' interest in that topic is frequently infectious. Even faculty who never would have wandered voluntarily into the valley of ethics often end up liking the visit.

Such experiences are, in my view, the most positive legacy of Stanford's pervasive ethics program. A substantial number of professors who once believed that "their" course was not about "that" now have stumbled on topics that they find interesting and important. Some even report that professional responsibility discussions are among their most successful classes.

It is a small step, but that, I suspect, is how curricula always evolve. We will need to lure, prod, and cajole colleagues into entering the valley of ethics, one by one, institution by institution. Many will be glad we did. Legal education will be richer for the effort. Law schools have long proclaimed their commitment to professional responsibility. It is time to translate rhetorical allegiance into curricular priorities.

30. See sources summarized in Rhode, Ethics by the Pervasive Method, supra note 4. 
